\title{
Optimum performance of capillary GC columns as a function of tube diameter and film thickness under various operating conditions. Computer program for calculation of H-.hivin.u curves and minimum analysis times
}

\section{Citation for published version (APA):}

Leclercq, P. A., \& Cramers, C. A. M. G. (1985). Optimum performance of capillary GC columns as a function of tube diameter and film thickness under various operating conditions. Computer program for calculation of $\mathrm{H}$ .hivin.u curves and minimum analysis times. HRC \& CC, Journal of High Resolution Chromatography and Chromatography Communications, 8(11), 764-771. https://doi.org/10.1002/jhrc.1240081112

DOI:

10.1002/jhrc. 1240081112

Document status and date:

Published: 01/01/1985

Document Version:

Publisher's PDF, also known as Version of Record (includes final page, issue and volume numbers)

Please check the document version of this publication:

- A submitted manuscript is the version of the article upon submission and before peer-review. There can be important differences between the submitted version and the official published version of record. People interested in the research are advised to contact the author for the final version of the publication, or visit the $\mathrm{DOI}$ to the publisher's website.

- The final author version and the galley proof are versions of the publication after peer review.

- The final published version features the final layout of the paper including the volume, issue and page numbers.

Link to publication

\footnotetext{
General rights

- You may freely distribute the URL identifying the publication in the public portal. follow below link for the End User Agreement:

www.tue.nl/taverne

\author{
Take down policy \\ If you believe that this document breaches copyright please contact us at: \\ openaccess@tue.nl \\ providing details and we will investigate your claim.
}

Copyright and moral rights for the publications made accessible in the public portal are retained by the authors and/or other copyright owners and it is a condition of accessing publications that users recognise and abide by the legal requirements associated with these rights.

- Users may download and print one copy of any publication from the public portal for the purpose of private study or research.

- You may not further distribute the material or use it for any profit-making activity or commercial gain

If the publication is distributed under the terms of Article 25fa of the Dutch Copyright Act, indicated by the "Taverne" license above, please 


\title{
Optimum Performance of Capillary GC Columns as a Function of Tube Diameter and Film Thickness under Various Operating Conditions ${ }^{* *}$
}

\section{Computer Program for Calculation of $\mathbf{H}-\bar{u}$ Curves and Minimum Analysis Times}

\author{
P. A. Leclercq and C. A. Cramers* \\ Laboratory of Instrumental Analysis, Eindhoven University of Technology, P.O. Box 513, 5600 MB Eindhoven, The Netherlands
}

\author{
Key Words: \\ Open tubular gas chromatography \\ Theory \\ Vacuum outlet \\ BASIC program for calculation of optimum conditions
}

\section{Summary}

The Golay-Giddings and Poiseuille equations are used to derive equations for the calculation of the maximum plate number and minimum time conditions for given columns at fixed, but selectable, outlet pressures. In addition, expressions are presented for the determination of minimum analysis times for separation problems requiring given plate numbers. In this instance, the optimum column length can be calculated as a function of outlet pressure. A Basic computer program, incorporating the equations for the various optima, together with the $\mathrm{H}-\overline{\mathrm{u}}$ curves, is described. Input variables are either column length or desired plate number, column diameter, film thickness, capacity ratio of the solute, column outlet pressure, separation temperature, and carrier gas. The carrier gas viscosity is automatically calculated in the case of hydrogen, helium, or nitrogen. For these gases, and if the solute is a $n$-alkane, the diffusivity of the solute in the mobile phase is calculated. In this case, the carbon number of the solute is needed in the computation.

For high molecular weight polydimethylsilicone phases (e.g. SE$30)$, the program can approximate the diffusivity of $n$-alkanes in the stationary phase at the given temperature as a function of the carbon number. Of course, manually entered values of viscosity and diffusion coefficients can be included in the calculations.

\section{Introduction}

As a result of advances in column technology, the chromatographer nowadays has a wide-ranging choice of open tubular columns. The column diameters are between "narrow-bore" and "wide-bore" (typically $10 \mu \mathrm{m}$ and $530 \mu \mathrm{m}$ ), and the stationary phase film thickness can be anywhere between 0 and $10 \mu \mathrm{m}$. These columns can be operated over a wide temperature range at outlet pressures from vacuum up to tens of bars.

In order to compare the actual performance of a column with that which can be theoretically achieved, the "coating

\footnotetext{
** Dedicated to Professor Kurt Grob in recognition of his invaluable contributions to capillary gas chromatography, particularly his work on column quality testing.
}

efficiency" is often used. In this comparison, the pressure drop correction factors $\left(f_{1}, f_{2}\right.$, see below) and the influence of the liquid phase are neglected. Therefore, the "coating efficiency" is meaningless for narrow-bore and/or thick-film columns [1]. Moreover, in many publications dealing with the speed of analysis obtainable by various columns, the plate numbers are often not constant. Therefore, exact equations for various optimum chromatographic conditions were derived, taking all pressure factors and the liquid mass-transfer term into account.

A computer program was developed for the calculation of these optimum conditions. This program can also calculate plate-height curves, again without neglecting any factors. This contrasts with the computer-constructed plate-height curves as published by Ingraham et al [2]

The Golay-Giddings plate-height equation for open tubular columns reads [3]:

$$
H=\left[\frac{B_{0}}{u_{0}}+C_{m, o} u_{0}\right] f_{1}+C_{s} u_{0} f_{2}
$$

In this equation the following symbols are used:

$$
\begin{aligned}
& B_{o}=2 D_{m, o} \\
& C_{m, 0}=\frac{11 k^{2}+6 k+1}{24(k+1)^{2}} \cdot \frac{r^{2}}{D_{m, 0}} \\
& C_{s}=\frac{2 k}{3(k+1)^{2}} \cdot \frac{d_{f}^{2}}{D_{s}}
\end{aligned}
$$

$D_{m, o}$ is the binary gas diffusion coefficient of a component in the mobile gas phase at column outlet pressure.

$D_{S}$ is the diffusion coefficient of the component in the stationary liquid phase.

$k$ is the capacity ratio of the component.

$r \quad$ is the inner column radius.

$d_{f} \quad$ is the film thickness of the stationary liquid phase.

$\mathrm{u}_{o} \quad$ is the linear gas velocity at the column outlet. 
Defining $P=p_{i} / p_{o}$ as the ratio of column inlet over outlet pressure:

$$
\begin{aligned}
& f_{1}=\frac{9}{8} \frac{\left(P^{4}-1\right)\left(P^{2}-1\right)}{\left(P^{3}-1\right)^{2}} \\
& f_{2}=\frac{3}{2} \frac{\left(P^{2}-1\right)}{\left(P^{3}-1\right)}
\end{aligned}
$$

If $P \rightarrow 1$, both $f_{1}$ and $f_{2}$ approach the value of 1 . If $P$ approaches infinity, $f_{1} \rightarrow 9 / 8$ and $f_{2} \rightarrow 3 /(2 P)$.

If a pressure gradient exists, decompression of the gas along the column causes its velocity to increase from inlet to outlet. For an ideal gas, both its linear velocity, $u$, and the binary solute/carrier gas phase diffusion coefficient $D_{m}$ vary inversely with pressure:

$$
\begin{aligned}
& u p=u_{i} p_{i}=u_{x} p_{x}=u_{o} p_{o} \\
& D_{m} p=D_{m, i} p_{i}=D_{m, x} p_{x}=D_{m, o} p_{o}
\end{aligned}
$$

with subscripts $i$ and o denoting inlet and outlet, and $x$ any position in the column.

Introducing the (time-)average linear gas velocity $\bar{u}=f_{2} u_{0}$, the (length-)average pressure $\bar{p}=p_{0} / f_{2}$, the atmospheric pressure $p_{a}$ (e.g. $p_{a}=100 \mathrm{kPa}=1 \mathrm{bar}$ ), and $u_{a}$ as the linear gas velocity at unit pressure $p_{a}$, eq. (7) can be extended to:

$$
\varepsilon=u_{\mathrm{i}} \mathrm{p}_{\mathrm{i}}=\mathrm{u}_{\mathrm{o}} \mathrm{p}_{\mathrm{o}}=\overline{\mathrm{u}} \overline{\mathrm{p}}=\mathrm{u}_{\mathrm{a}} \mathrm{p}_{\mathrm{a}}
$$

Under constant operational conditions $\varepsilon$ is a constant. Combination of eqs. (8) and (9) shows:

$$
\frac{D_{m, 0}}{u_{o}}=\frac{D_{m, a}}{u_{a}}=\frac{D_{m, a} p_{a}}{\varepsilon}
$$

with $D_{m, a}$ denoting the binary gas diffusion coefficient at unit pressure $p_{a}$. Giving $B$ and $C_{m}$ the same subscript as the corresponding $D_{m}$, eq. (1) can now be rewritten as:

$$
H=\left[\frac{B_{a} p_{a} f_{1}}{\varepsilon^{2}}+\frac{C_{m, a} f_{1}}{p_{a}}+\frac{C_{s}}{\bar{p}}\right] \varepsilon
$$

or:

$$
\varepsilon=p_{a}\left[\frac{\frac{H \varepsilon}{p_{a}}-B_{a} f_{1}}{C_{m, a} f_{1}+C_{s} \cdot \frac{p_{a}}{\bar{p}}}\right]^{\frac{1}{2}}
$$

Note that the square root term represents $u_{a}$, the velocity at atmospheric pressure.

Eq. (11) shows that $H=f(\bar{u})$ cannot be straightforwardly evaluated, because $\varepsilon, \bar{p}$, and $f_{1}$ cannot be expressed generally as simple functions of $\bar{u}$. However, eq. (11) can be rearranged to:

$$
\frac{H}{\bar{u}}=\left[\frac{B_{a} p_{a}}{\varepsilon^{2}}+\frac{C_{m, a}}{p_{a}}\right] f_{1} \bar{p}+C_{s}
$$

which can be considered to be exclusively pressure dependent, because $\varepsilon$ is given by the Hagen-Poiseuille equation for viscous flow of ideal gases through open tubular columns:

$$
\varepsilon=\frac{r^{2} p_{o}^{2}}{16 \eta \underline{L}}\left(P^{2}-1\right)=\frac{r^{2}}{16 \eta \underline{L}}\left(p_{i}^{2}-p_{o}^{2}\right)
$$

where $\eta$ is the dynamic viscosity of the carrier gas, and $L$ is the column length.

For a given column operated at constant outlet pressure $p_{0}$ and otherwise constant conditions, the values of $f_{1}, \bar{p}=$ $p_{o} / f_{2}$ and $\varepsilon$ are determined by $p_{i}$ only, see eqs. (5), (6), and (14). Therefore, $H / \bar{u}=f\left(p_{i}\right)$ can be evaluated. Subsequently, for any value of $p_{i}, \bar{u}=\varepsilon / \bar{p}$ can be calculated from eq. (14). Hence $\mathrm{H}=\mathrm{f}(\overline{\mathrm{u}})$ can be obtained by multiplying eq. (13) by $\overline{\mathrm{u}}$.

Eq. (14) can be rearranged to:

$$
p_{i}^{2}=\frac{16 \eta L}{r^{2}} \varepsilon+p_{o}^{2}
$$

By combination of eq. (11) or (12) with (14) or (15) various optimum conditions can be calculated.

\section{Optimum Chromatographic Conditions}

Cramers et al. [3] derived the minimum of the $\mathrm{H} v \mathrm{vs}$. $\mathrm{u}_{0}$ function (at constant $p_{o}$ ) by differentiation of eq. (1) with respect to $u_{0}$. The derivatives $\delta f_{1} / \delta u_{o}$ and $\delta f_{2} / \delta u_{0}$ were calculated as $(\delta f / \delta P)\left(\delta P / \delta u_{0}\right)$. [The latter derivative follows from eq. (14): $\delta \mathrm{u}_{0} / \delta \mathrm{P}=\mathrm{u}_{\mathrm{o}} 2 \mathrm{P} /\left(\mathrm{P}^{2}-1\right)$.] These authors found an "optimum" outlet velocity, corresponding to minimum plate height, of:

$$
u_{0, \text { opt" }}=\left[\frac{B_{0}\left(f_{1}-y_{1}\right)}{c_{m, o}\left(f_{1}+y_{1}\right)+C_{s}\left(f_{2}+y_{2}\right)}\right]^{\frac{1}{2}}
$$

After elaboration, their $y$-factors appear to equal:

$$
\begin{aligned}
& y_{1}=u_{o} \delta f_{1} / \delta u_{o}=f_{1}-f_{2} P\left(f_{1}-f_{2} P\right) \\
& y_{2}=u_{o} \delta f_{2} / \delta u_{o}=f_{2}\left(1-f_{2} P\right)
\end{aligned}
$$

Note that $f_{2} P=p_{/} / \bar{p}$ and $1<f_{2} P<3 / 2$ for $0<P<\infty$.

Using eqs. (9), (10), (17), and (18), eq. (16) can be rearraned into:

$$
\varepsilon_{\min H}=p_{a}\left[\frac{B_{a} f_{2} P\left(2 f_{1}-f_{2} P\right)}{C_{m, a}\left[2 f_{1}-f_{2} P\left(2 f_{1}-f_{2} P\right)\right]+C_{s} \frac{p_{a}}{\bar{p}}\left(2-f_{2} P\right)}\right]^{\frac{1}{2}}
$$

The same authors showed that $y_{1} \ll f_{1}$ for all practical purposes, meaning that $f_{1} \approx f_{2} P\left(2 f_{1}-f_{2} P\right)$, see eq. (17). ( $y_{1}$ reaches a maximum of $3.19 \%$ of $f_{1}$ at $P=2.56$.) Eq. (19) can, therefore, be simplified to:

$$
\varepsilon_{\min H} \approx p_{a}\left[\frac{B_{a} f_{1}}{C_{m, a} f_{1}+C_{s} \frac{p_{a}}{\bar{p}}\left(2-f_{2} P\right)}\right]^{\frac{1}{2}}
$$


Often, chromatographers are more interested in minimum time operation. Since the retention time $t_{R}=(1+k) L / \bar{u}$, and $\mathrm{L}=\mathrm{NH}$, where $\mathrm{N}$ represents the column plate number, the ratio $H / \bar{u}=t_{R} / N /(1+k)$ should be minimized. Hence, eq. (13) should be differentiated. For a given column ( $L=$ constant), $\delta(H / \bar{u}) / \delta \bar{u}=0$ yields for $p_{0}=$ constant.

$$
\varepsilon_{L, \min t}=p_{a}\left[\frac{B_{a}}{C_{m, a}} \cdot \frac{2 f_{1}+f_{2} P\left(f_{1}-f_{2} P\right)}{f_{2} P\left(f_{2} P-f_{1}\right)}\right]^{\frac{1}{2}}
$$

In deriving this result $\delta P / \delta \bar{u}$ and $\delta \bar{p} / \delta \bar{u}$ were calculated as the reciprocals of the respective derivatives of eq. (14), using $\delta \bar{p} / \delta P=\bar{p}\left(f_{2} P-1\right) .2 P /\left(P^{2}-1\right)$.

For a given column ( $L$ and $r$ constant) and a given carrier gas/stationary phase/solute system at a given temperature $\left(\eta, D_{m}, a^{\prime} k, D_{s}, d_{f}\right.$ constant) and outlet pressure $\left(p_{o}=\right.$ constant), the optimum inlet pressures can now be calculated numerically by interation from eq. (15), using the optimum $\varepsilon$ values given by eq. (19), (20), or (21).

Using $\bar{p}==p_{0} / f_{2}$ and $\bar{u}=\varepsilon / \bar{p}$, the corresponding $H$ values can then be calculated from eq. (11).

In addition to maximum plate number and separation speed for a given column, there is a third optimum: the minimum analysis time for a given separation problem requiring $\mathrm{N}$ plates. For this purpose eq. (15) can be rewritten as:

$$
\mathrm{p}_{\mathrm{i}}^{2}=\frac{16 \eta N}{r^{2}} H \varepsilon+\mathrm{p}_{\mathrm{o}}^{2}
$$

and hence the optimum value of $\mathrm{H} \varepsilon$ has to be determined. Combination of eqs. (11) and (12) yields:

$$
\frac{H}{\bar{u}}=\frac{C_{m, a} \bar{p} f_{1} / p_{a}+C_{s}}{1-B_{a} p_{a} f_{1} /(H \varepsilon)}=\frac{\text { numerator }}{\text { denominator }}
$$

Substitution of $\mathrm{H \varepsilon}$ from eq. (22) yields another pressuredependent plate height equation. Therefore, minimum time conditions for $\mathrm{N}=$ constant are best calculated (for $\mathrm{p}_{0}$ = constant) via:

$$
\begin{aligned}
\frac{\delta(\mathrm{H} / \overline{\mathrm{p}})}{\delta \mathrm{P}} & =\frac{\delta \text { (numerator) } / \delta \mathrm{P}}{\text { denominator }}-\frac{\text { numerator }}{\text { denominator }^{2}} \\
& \cdot \frac{\delta(\text { denominator })}{\delta \mathrm{P}}
\end{aligned}
$$

Hence, putting the result equal to zero:

$$
\frac{\mathrm{H}}{\overline{\mathrm{u}}}=\frac{\delta \text { (numerator }) / \delta \mathrm{P}}{\delta \text { (denominator) } / \delta \mathrm{P}}
$$

Eq. (25) can be evaluated as:

$$
\frac{H}{\vec{u}}=\frac{C_{m, a} p_{a}\left[\frac{\left(f_{2} P\right)^{2}+f_{1}\left(2-2 f_{2} P\right)}{f_{2}\left(2-f_{2} P\right)}\right]}{1-\frac{B_{a} p_{a}}{H \varepsilon}}\left[\frac{\left(f_{2} P\right)^{2}+f_{1}\left(2-3 f_{2} P\right)}{\left(2-f_{2} P\right)}\right]+C_{s}
$$

Combination of eqs. (23) and (26) yields:

$$
H \varepsilon=-B_{a} p_{a} \frac{f_{1}^{2} C_{m, a}+C_{s}\left(2 f_{1}-f_{2} P\right) p_{a} / \bar{p}}{C_{m, a}\left(f_{1}-f_{2} P\right)}
$$

Using eq. (22), $p_{i}$ can now be numerically calculated by iteration. Once $p_{i, o p t}$ is determined, all pressure factors can be caiculated and $\varepsilon$ is found by substitution of eq. (27) into eq. (12):

$$
\varepsilon_{N, \min t}=p_{a}\left[\frac{B_{a}}{C_{m, a}} \cdot \frac{\left(2 f_{1}-f_{2} P\right)}{\left(f_{2} P-f_{1}\right)}\right]^{\frac{1}{2}}
$$

\section{Vacuum Outlet}

The equations derived thus far are generally valid for open tubular columns. At $p_{o} \rightarrow 0$, or $P \rightarrow \infty$ in general, most equations are greatly simplified. Under $P \rightarrow \infty$ conditions, $f_{1} \rightarrow 9 / 8$, $f_{2} P \rightarrow 3 / 2, \bar{p} \rightarrow 2 p_{i} / 3$, and eq. (14) reduces to:

$$
\varepsilon \rightarrow \frac{r^{2}}{16 \eta L} \quad p_{i}^{2}=\frac{64 \eta L}{9 r^{2}} \bar{u}^{2}
$$

Using these limiting values, eq. (11) can be written as:

$$
H_{P \rightarrow \infty}=\left[\frac{B_{a} p_{a} X}{p_{i}^{2}}+\frac{C_{m, a}}{p_{a} X} p_{i}^{2}\right] \frac{9}{8}+\frac{3}{2} C_{s} p_{i} X
$$

with $X=16 \eta L / r^{2}$. Eq. (30) was already derived by Myers and Giddings [4].

As an alternative,

$$
H P \rightarrow \infty=\left[\frac{9 B_{a} p_{a}}{4 X \bar{u}^{2}}+\frac{4 C_{m, a} X}{9 p_{a}} \bar{u}^{2}\right] \frac{9}{8}+C_{s} \bar{u}
$$

Both the exclusively pressure or velocity dependent eqs. (30) and (31) are of practical importance for high pressure or vacuum outlet chromatography. (Computer) fitting of these expressions to experimental data is preferred over fitting of eq. (1), because $u_{0}$ and $B_{0}$ are extremely large at vacuum outlet, while $C_{m, o}$ and $f_{2}$ are extremely small. Moreover, $p_{i}$ and $\bar{u}$ can always be measured conveniently.

\subsection{Optimum Conditions for Vacuum Outlet}

The four eqs. (19), (20), (21), and (28), giving the $\varepsilon$ expressions for the various optima, reduce to a set of three 
expressions, eqs. (19) and (20) leading to identical results for $P \rightarrow \infty$ :

$$
\begin{aligned}
& \varepsilon_{P \rightarrow \infty, \min H}=p_{a}\left[\frac{3 B_{a}}{3 C_{m, a}+C_{s} \frac{p_{a}}{p_{i}}}\right]^{\frac{1}{2}} \\
& \varepsilon_{P \rightarrow \infty, L, \min t}=p_{a}\left[\begin{array}{l}
3 B_{a} \\
C_{m, a}
\end{array}\right]^{\frac{1}{2}} \\
& \varepsilon_{P \rightarrow \infty, N, \min t}=p_{a}\left[\begin{array}{l}
2 B_{a} \\
C_{m, a}
\end{array}\right] \frac{1}{2}
\end{aligned}
$$

Eq. (27) reduces to:

$$
\mathrm{H} \varepsilon=3 \mathrm{~B}_{\mathrm{a}} \mathrm{p}_{\mathrm{a}}\left[\begin{array}{ll}
\frac{9}{8}+\frac{\mathrm{C}_{\mathrm{s}}}{\mathrm{C}_{\mathrm{m}, \mathrm{a}}} & \mathrm{p}_{\mathrm{a}}
\end{array}\right]
$$

A similar result was already presented in 1962 by Giddings [5], who introduced the concept of "critical inlet pressure" $p_{\mathrm{c}}$ :

$$
p_{c}^{2}=18 \eta n B_{a} p_{a} / r^{2}=\frac{9}{8} B_{a} p_{a} X / H
$$

The relation between $\mathrm{H} \varepsilon$ and $\mathrm{p}_{\mathrm{c}}$ is given by:

$$
\mathrm{H} \varepsilon=\frac{9}{8} \mathrm{~B}_{\mathrm{a}} \mathrm{p}_{\mathrm{a}}\left[\begin{array}{l}
\mathrm{p}_{\mathrm{i}} \\
\mathrm{p}_{\mathrm{c}}
\end{array}\right]^{2}
$$

Using eq. (29), eqs. (32) -(34) can be rewritten as functions of $p_{i}^{2}$. Neglecting the $C_{s}$-term in eq. (32) the results are condensed as:

$$
\mathbf{p}_{\mathrm{i}}^{2}=\mathrm{p}_{\mathrm{a}} \mathrm{x}\left[\begin{array}{l}
n \cdot \mathrm{B}_{\mathrm{a}} \\
\mathrm{C}_{\mathrm{m}, \mathrm{a}}
\end{array}\right]^{\frac{1}{2}}
$$

with $n=1$ for minimum plate height conditions, $n=3$ for minimum time conditions for a given column ( $L=$ constant) and $n=2$ for minimum analysis time for a requested plate number ( $N=$ constant). Substitution of eqs. (32)-(34) in eq. (11) yields:

$$
\begin{aligned}
& {\left[\begin{array}{c}
H \\
\bar{u}
\end{array}\right]_{\min H}=\frac{3}{2} \frac{p_{i}}{p_{a}} C_{m, a}+\frac{3}{2} C_{s}} \\
& {\left[\begin{array}{c}
H \\
\bar{u}
\end{array}\right]_{L, \min t}=\frac{p_{i}}{p_{a}} C_{m, a}+C_{s}} \\
& {\left[\begin{array}{c}
H \\
\bar{u}
\end{array}\right]_{N, \min t}=\frac{9}{8} \frac{p_{i}}{p_{a}} C_{m, a}+C_{s}}
\end{aligned}
$$

The inlet pressures can be expressed as a function of $p_{c}$. Eq. (37) can be converted into:

$$
p_{i}^{2}=\frac{8}{9} p_{c}^{2} \frac{H}{\varepsilon} \frac{\varepsilon^{2}}{B_{a} p_{a}}
$$

which after substitution of eq. (11) yields:

$$
p_{i}^{2}=p_{c}^{2}\left[1+\left[\begin{array}{ccc}
C_{m, a} \\
p_{a}
\end{array}+\frac{4}{3} \frac{C_{s}}{p_{i}}\right] \begin{array}{c}
\varepsilon^{2} \\
B_{a} p_{a}
\end{array}\right]
$$

Insertion of the three $\varepsilon$ values from eqs. (32)-(34) gives:

$$
\begin{aligned}
& p_{i, \min H}^{2}=2 p_{c}^{2}\left[\frac{\frac{p_{i}}{p_{a}} c_{m, a}+c_{s}}{\frac{p_{i}}{p_{a}} c_{m, a}+\frac{2}{3} c_{s}}\right] \\
& p_{i, L, \min t}^{2}=4 p_{c}^{2}\left[\frac{\frac{p_{i}}{p_{a}} c_{m, a}+C_{s}}{\frac{p_{i}}{p_{a}} c_{m, a}}\right] \\
& p_{i, N, \min t}^{2}=3 p_{c}^{2}\left[\frac{\frac{p_{i}}{p_{a}} c_{m, a}+\frac{8}{9} C_{s}}{\frac{p_{i}}{p_{a}} c_{m, a}}\right]
\end{aligned}
$$

For thin film columns $\left(C_{s} \ll C_{m, a}\right)$, eqs. (44)-(46) reduce to $p_{i}^{2}=n . p_{c}^{2}$ with $n=2($ minimum $H), n=4$ (minimum $t, L$ constant) and $n=3$ (minimum $t, N$ constant). Note that $p_{c}$ or $L$ are generally not equal in these instances.

The retention time is given by:

$$
t_{R}=N(1+k) \frac{H}{\bar{u}}
$$

Hence, combination with eqs. (39)-(41) yields for vacuum outlet operation of thin-film columns:

$$
\begin{aligned}
& t_{R, \min H}=N(1+k) \frac{3}{2} \sqrt{2} \frac{p_{c}}{p_{a}} C_{m, a} \\
& t_{R, L, \min t}=N(1+k) 2 \frac{p_{c}}{p_{a}} C_{m, a} \\
& t_{R, N, \min t}=N(1+k) \frac{9}{8} \sqrt{3} \frac{p_{c}}{p_{a}} C_{m, a}
\end{aligned}
$$

The factors $3 \sqrt{2} / 2: 2: 9 \sqrt{3} / 8$ are $2.12: 2: 1.95$.

Substitution of eqs. (36), (2), and (3) in eqs. (48)-(50) gives:

$$
t_{R}=n r N^{3 / 2} \frac{11 k^{2}+6 k+1}{4(k+1)}\left[\frac{\eta}{p_{a} D_{m, a}}\right]^{\frac{1}{2}}
$$

where $\mathrm{n}$ represents the above-mentioned factors from eqs. (48)-(50). Combination of eq. (51) with the well-known resolution equation [6]:

$$
\mathrm{R}=\frac{1}{4} \frac{\mathrm{k}}{\mathrm{k}+1} \frac{\alpha-1}{\alpha} \mathrm{N}^{\frac{1}{2}}
$$

by elimination of $\mathrm{N}$ yields: 


$$
\begin{aligned}
t_{R}= & 16 n R^{3} r \frac{(k+1)^{2}\left(11 k^{2}+6 k+1\right)}{k^{3}} \times \frac{\alpha^{3}}{(\alpha-1)^{3}} \times \\
& {\left[\frac{\eta}{P_{a} D_{m, a}}\right]^{\frac{1}{2}} }
\end{aligned}
$$

where $\alpha$ is the relative retention of two peaks separated with resolution R. Eq. (53) has been published before by Guiochon [7] and Leclercq et al. [8]. The constant 16n equals $24 \sqrt{2}(=33.9), 32$, and $18 \sqrt{3}(3=31.2)$ for the three optima, respectively. Minimum retention times are obtained for $k=1.76[7]$.

\section{Computer Program}

A Basic program was designed to calculate $\mathrm{H}-\mathrm{u}$ curves and the various optimum chromatographic conditions. The input required is:

- L given (in meter) or $\mathrm{N}$ required; the program automatically selects the appropriate mode. If $Y=$ input $>1000$ then $Y=$ plate number. This is very convenient, because eqs. (15) and (22) can be interchanged throughout the program.

$-r, d_{f}$, the separation temperature $T$ (in Kelvin) and $k$ are requested. (It is advised to employ temperatures at which $\mathrm{k}$ is between 1 and 2, i.e. around the optimum value of 1.76.) The carrier gas is asked for. For hydrogen, helium, or nitrogen, the program calculates the viscosity according to Ettre [9]. (His equations 27, 21, and 23, respectively.)

For other gases, or upon the user's request, the program asks for a value of $\eta$ at a temperature $T_{1}$. IF $T_{1} \neq T, \eta$ is calculated as:

$$
\eta=\eta_{T_{1}}\left(T / T_{1}\right)^{0.7}
$$

- If the carrier gas is $\mathrm{H}_{2}, \mathrm{He}$, or $\mathrm{N}_{2}$, the program will ask for the carbon number of the solute, provided it is a $n$-alkane. A subroutine then calculates the binary gas phase diffusion coefficient according to Fuller et al. [10]:

$D_{m, a}=\frac{T^{1.75}\left[\frac{1}{M}+\frac{1}{14 C+2}\right]^{1}}{10\left[V^{1 / 3}+[16.5 C+1.98(2 C+2)]^{1 / 3}\right]^{2}}$

where $M$ and $V$ are the molecular weight and diffusion volume of the carrier gas, and $\mathrm{C}=$ carbon number of the $n$-alkane. (The dimension of $D_{m, a}$ is $\mathrm{mm}^{2} / \mathrm{s}$.)

For other carrier gas/solute combinations, or if the user is not satisfied with the result, $D_{m, a}$ at $T_{2}$ is inputted. If $T_{2} \neq T$, the program calculates:

$$
D_{m, a}=D_{m, a, T_{2}}\left(T / T_{2}\right)^{1.75}
$$

- $D_{5}, T_{3}$ is requested. The program can extrapolate $D_{S}$ values if $T_{3} \neq T$, but the result is only meaningful for $n$-alkanes on SE-30 phases and within a temperature range of $\mathrm{T}_{3}$ $\pm 50 \mathrm{~K}$.
If $T_{3} \neq T$ the program will calculate $D_{S}$ as $[11,12]$ :

$$
D_{S}=D_{S, T_{3}} \cdot e^{(225-250 C)\left(1 / T-1 / T_{3}\right)}
$$

- Finally, $p_{0}$ is asked for.

The program now calculates $\mathrm{B}_{a}, \mathrm{C}_{m, a}$, and $\mathrm{C}_{5}$ according to eqs. (2), (3), (4), and (10). Then the optimum conditions can be calculated for a given column $(Y=L)$ or a requested plate number $(Y=N)$. First $X=16 \eta Y / r^{2}$ is calculated, a factor needed in eq. (15) or (22). Next all pressure factors $\left(P, f_{1}\right.$, $\left.f_{2} P, \bar{p}\right)$ are calculated by a subroutine, using a starting value for the inlet pressure of $p_{i}=p_{o}+p_{a}$.

Based on the value of $Y$, the program diverts to the appropriate section. If $L$ is given $(Y<1000)$, $\varepsilon$ is calculated from eq. (19). The result is substituted into eq. (15), yielding a new value of $\mathrm{p}_{\mathrm{i}}$. This value of $\mathrm{p}_{\mathrm{i}}$ is used as input to the before mentioned subroutine which recalculates all pressure factors.

The results are used to recalculate $\varepsilon$ from eq. (19) and subsequently a new value of $p_{i}$ from eq. (15). In this way the optimum $\varepsilon$ is iteratively approached as long as the latest value of $\mathrm{p}_{i}$ differs more than $1 \mathrm{~Pa}$ (i.e. $10^{-5} \mathrm{p}_{\mathrm{a}}$ ) from its lastbut-one value.

Having optimized $\varepsilon, \mathrm{p}_{\mathrm{i}}$, and all pressure factors, another subroutine is used to calculate $\bar{u}$ from eq. (9), $\mathrm{H}$ from eq. (11), $N=L / H, t_{R}$ from eq. (47), $N / L$ and $N / t_{R}$.

Next the $\varepsilon$ from eq. (20) and subsequently $\varepsilon$ from eq. (21) are calculated by iteration in exactly the same manner as described for $\varepsilon_{\min } H$.

If $N$ is given ( $Y>1000$ ), $\varepsilon H$ is optimized by iteration using eqs. (27) and (22), again by repeatedly using the pressure factor subroutine as described above. This iteration converges slower than those for a given column, especially at elevated outlet pressures. Moreover, the repeated calculations of $\varepsilon H$ (eq. 27) and $p_{i}$ (eq. 22) sometimes lead to an infinite loop when the exit criterion is $p_{i, n e w}-p_{i \text {,last }}<1 \mathrm{~Pa}$. Therefore, in this case the optimum $p_{i}$ is approached to within $\pm 5 \mathrm{~Pa}$. Upon exit, the resulting $\mathrm{p}_{\mathrm{i}}$ and pressure

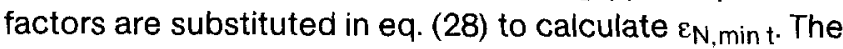
subsequent program flow is the same as described above for $L=$ constant, but using $L=N H$ in the various equations.

Upon completion of the optimization procedures, the $\mathrm{H}-\overline{\mathrm{u}}$ curve can be computed from eqs. (13) and (14), as described under eq. (14). The $\mathrm{H}-\overline{\mathrm{u}}$ curve is calculated and printed on request, for inlet pressures in the range of about $\bar{p}_{\min H}$ to $2 p_{i, \min H}$. Finally, one or more of the input data can be changed and the program restarted.

\section{Results and Discussion}

As an example, the program was used to predict the various optimum conditions for a wide-bore, thick-film SE-30 column, operated with hydrogen carrier gas at atmospheric (Table 1) and vacuum outlet conditions (Table 2). 
Table 1

Comparison of calculated and measured optima. Atmospheric outlet conditions.

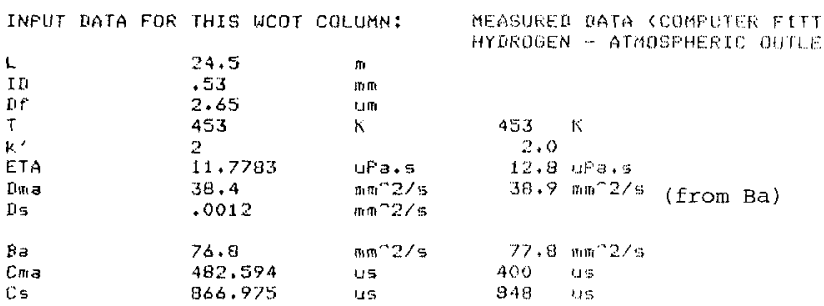

OPTIMUM CHFOMATOGFAFHIC CONDITLONS FOF PO $=100 \mathrm{KF}$

MINIMUM FLATE HETGHT CONDITLONS FOOR THIS COLUMN: (EGS. 19 \& 11) (GDLAY - GILIILGGS)

\begin{tabular}{|c|c|c|c|c|}
\hline $\mathrm{Fi}$ & 107.73 & $\mathrm{RFB}$ & 108 & F.F \\
\hline is (averase) & .235044 & atis $/ \mathrm{s}$ & 246 & thes $/ \mathrm{s}$ \\
\hline H & .636287 & $\ln$ & 615 & $1.017 \pi$ \\
\hline$t(R)$ & 312.708 & 5 & 299 & 5 \\
\hline$N$ & 38504.6 & & 39848 & \\
\hline$N / L$ & 1571,62 & $m^{n}-1$ & & \\
\hline$N / t(R)$ & 123.133 & $5^{m}-1$ & & \\
\hline$F C$ (GIDIINGS) & 29.8791 & $\mathrm{~Pa}$ & & \\
\hline Fil & 3.60554 & & & \\
\hline+1 & 1.00046 & & & \\
\hline$f_{2}$ & .962338 & & & \\
\hline$\beta$ (average) & 103.914 & A.Fa & & \\
\hline
\end{tabular}

MINIMUM FLATE HEIGHT CONDTTIONS (CFAMERS): (EqS. 20 \& 11)

\begin{tabular}{|c|c|c|}
\hline$P i$ & 107.735 & $\mathrm{KFO}$ \\
\hline us (averase) & .235182 & $\pi / s$ \\
\hline & .636291 & $\min$ \\
\hline$t(R)$ & 312.524 & $s$ \\
\hline $\mathrm{N}$ & 38504.4 & \\
\hline$N / L$ & 1571.61 & $m^{-}-1$ \\
\hline$N / t(R)$ & 123.205 & $5^{-2}-1$ \\
\hline OC (GIDIINGS) & 29.879 & 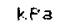 \\
\hline pi/kc & 3.6057 & \\
\hline fi & 1.00046 & \\
\hline$f_{2}$ & .982323 & \\
\hline o (average) & 103,915 & $k P a$ \\
\hline
\end{tabular}

(averase) 103.915 kFa

MINIMUM TIME CONIITIONS FOR THIS

\begin{tabular}{|c|c|c|}
\hline Fi & 137.488 & HFD \\
\hline$\lrcorner$ (averase) & 1.131 & $\pi / 5$ \\
\hline & 1.69851 & \\
\hline$t(R)$ & 64.967 & $\Leftrightarrow$ \\
\hline N & 14441.4 & \\
\hline$N / 2$ & 589.444 & $\pi^{2}-1$ \\
\hline$N / t(F)$ & 222.219 & $s^{-1}$ \\
\hline OC (GIILINGS) & 18.2985 & $\mathrm{KFa}$ \\
\hline $\begin{array}{l}\text { Pijoc } \\
\text { risc }\end{array}$ & 7.51364 & \\
\hline $\mathrm{fl}$ & 1.0031 & \\
\hline 12 & .835213 & \\
\hline P (average) & 119.73 & p. $\cdots$ \\
\hline
\end{tabular}

The $\mathrm{H}-\bar{u}$ curves of this column were measured with $n$-dodecane as a test compound. The separation temperature of $453 \mathrm{~K}$ was tuned to a capacity ratio of $\mathrm{k}=2.0$ for this solute.

The computer program calculated a good value of the carrier gas viscosity, but the diffusion coefficients were off by about $20 \%$, as expected for this solute [10-12]. Therefore, literature data of the diffusivities [10-12] were entered manually as listed in Table 1.

The experimentally acquired data were fitted to eqs. (1) and (31), for atmospheric and vacuum outlet, respectively [13]. The results from these fits are included in Tables 1 and 2 in the columns "measured".

As can be seen, there is a good agreement between calculated and measured data. Another conclusion is that the approximation of minimum plate-height conditions by Cramers et al. [3] is indeed very good.
Table 2

Comparison of calculated and measured optima. Vacuum outlet conditions.

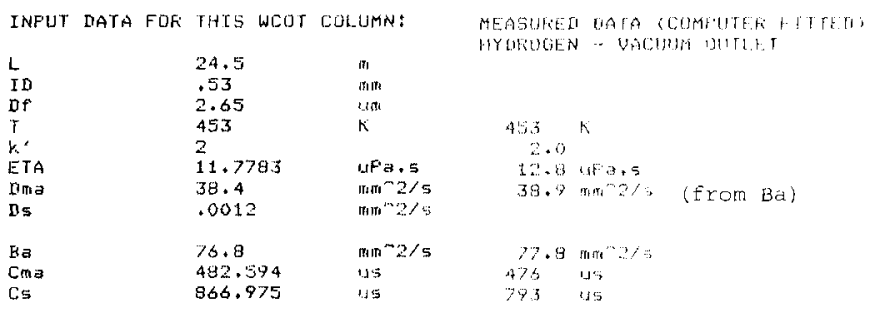

QFTIMUM CHFOMATOGRAPHIC CONOITTONS FOL

MINIMUM FLATE HELOHT CONIITIONS FOF THIS COLUMA: (EGS. 19 \& 11 ) GGOLAY - GIUIINGS)

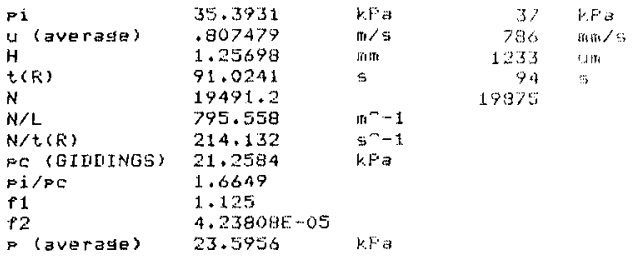

MINIMUM FLATE HEIGHT CONDTTLONS (CFAMERS): (EqS. $20 \& 11$ )

\begin{tabular}{|c|c|c|}
\hline $\mathrm{Pi}$ & 35.3931 & $K P a$ \\
\hline u (average) & .807479 & $m / s$ \\
\hline & 1.25698 & miln \\
\hline$t(R)$ & 91.0241 & $s$ \\
\hline N & $19491+2$ & \\
\hline$N / L$ & 795.558 & $m^{2}-1$ \\
\hline$N / t(R)$ & 214.132 & \\
\hline F (GIDUINGS) & 21.2584 & \\
\hline FISFC & 1.6649 & \\
\hline$f^{\prime} 1$ & 1.125 & \\
\hline $\mathrm{f} 2$ & $4.23808 E-0$ & \\
\hline P (avenase) & 23.5956 & $K F 3$ \\
\hline
\end{tabular}

P (averase) 23.5956 kta

MINIMUM TIME CONDTTIONS FOF THLG COLHMN (LECLEFCO): (EQS. 21 \& 11 )

\begin{tabular}{|c|c|c|}
\hline 81 & 67.4004 & KFo \\
\hline $\begin{array}{l}u \\
H\end{array}$ (zverase) & $\begin{array}{l}1.53772 \\
1.83334\end{array}$ & $m / s$ \\
\hline$t(R)$ & 47.798 & s \\
\hline $\mathrm{N}$ & 13363.6 & \\
\hline$N / L$ & 545.452 & $m^{n^{2}-1}$ \\
\hline$N / t(R)$ & 279.564 & $5^{n}-1$ \\
\hline$P C$ (GIDUINGS) & 17.6024 & $R F^{2} ; 3$ \\
\hline $\mathrm{Pi} / \mathrm{PC}$ & 3.82904 & \\
\hline 11 & 1.125 & \\
\hline 12 & $2.22551 E-05$ & \\
\hline o (averase) & 44.9336 & r.F \\
\hline
\end{tabular}

Minimum analysis time is achieved only at vacuum outlet operation $[5,8]$. As a test, the plate number calculated for minimum time conditions with the given $24.5 \mathrm{~m}$ column at $p_{0}=0,(N=13364)$, was inputted to the program instead of the column length. The results of the calculations are shown in Table 3. The calculated column length is $22.8 \mathrm{~m}$. As expected from the presented theory, and particularly demonstrated for thin-film columns, viz. eqs. (49), (50), and (53), these results define the real minimum time conditions. the values of $\mathrm{N} / \mathrm{t}_{\mathrm{R}}$ to be compared from Tables 2 and 3 are 279.6 and 281.0 plates per second, respectively. The differences between the minimum retention times for a given column and for a required plate number under similar conditions cannot yet be fully comprehended, however.

Table 4 exemplifies a plate-height curve print-out for the column of Table 2. 
Table 3

Calculated minimum time conditions for $\mathrm{N}=13364$ plates. (cf. Table 2).

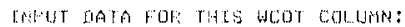

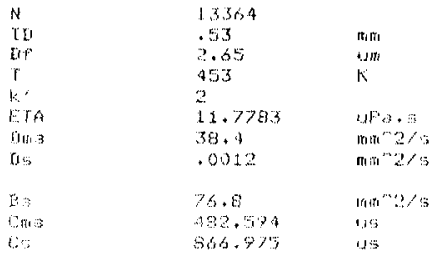

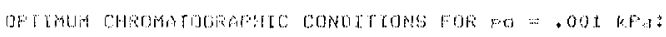

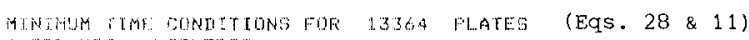

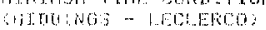

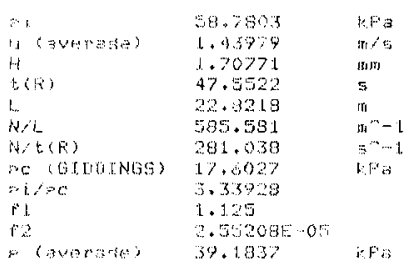

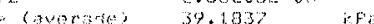

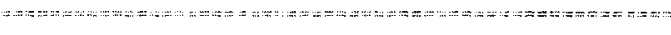

The program and its subroutines were found to be very reliable in numerous calculations. Widely varying input data, and particularly $p_{o}=0$ (vacuum outlet) conditions are treated without problems, yielding accurate results. Vacuum outlet data produced by the program (using the general equations) are identical to those obtained by employing the eqs. (32) $-(35)$ and (29) derived for $P \rightarrow \infty$.

The good results are produced because the program does not work with extreme values (except in the pressure factor subroutine). In the iterations mostly $f_{2} P$, with a value between 1 and 1.5 , is employed although $f_{2}$ and $P$ might approach zero and infinity, respectively.

\section{Acknowledgment}

The program is written in minimal Basic and will run on most (personal) computers. The program can be obtained from the first author.

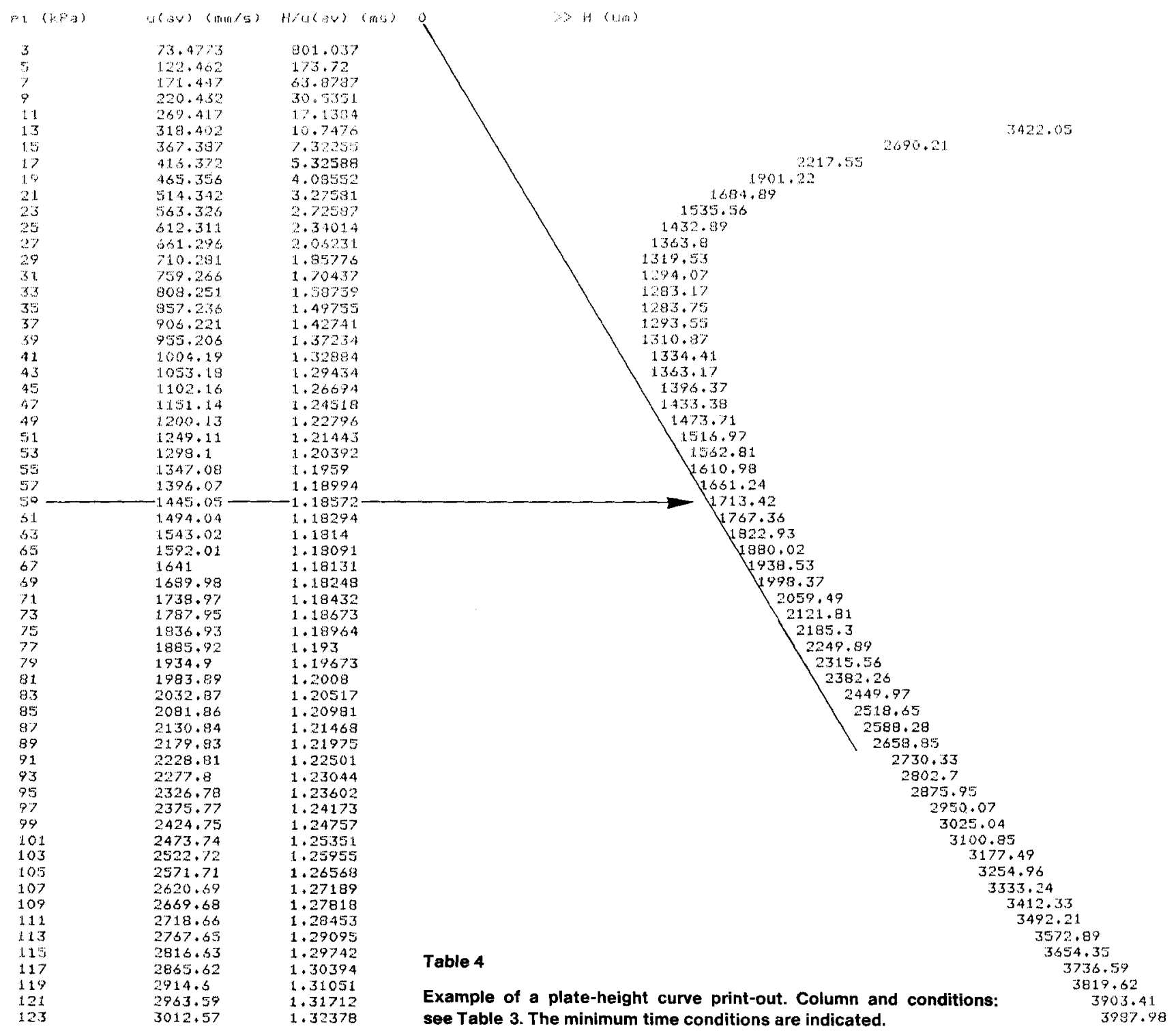




\section{References}

[1] C. A. Cramers, F. A. Wijnheymer, and J. A. Rijks, Chromatogra phia 12 (1979) 643.

[2] D.F.Ingraham, C.F. Shoemaker, and W. Jennings, HRC\&CC 5 (1982) 227.

[3] C. A. Cramers, F. A. Wijnheymer, and J. A. Rijks, HRC \& CC 2 (1979) 329.

[4] M.N. Myers and J. C. Giddings, Anal. Chem. 37 (1965) 1453.

[5] J. C. Giddings, Anal. Chem. 34 (1962) 314.

[6] L. S. Ettre, "Open Tubular Columns; An Introduction", PerkinElmer, Norwalk, Conn. (1973) p. 13.

[7] G. Guiochon, Anal. Chem. 50 (1978) 1812.
[8] P. A. Leclercq, C. P. M. Schutjes, and C. A. Cramers, in F. Bruner, Ed., "The Science of Chromatography" (J. Chromatogr. Libr., Vol. 32), Elsevier, Amsterdam (1985) p. 55.

[9] L. S. Ettre, Chromatographia 18 (1984) 243.

[10] E. N. Fuller, P.D. Schettler, and J. C. Giddings, Ind. Eng. Chem. 58 (1966) 19.

[11] J. M. Kong and S. J. Hawkes, J. Chromatogr. Sci. 14 (1976) 279.

[12] W. Millen and S. J.Hawkes, J. Chromatogr. Sci. 15(1977) 148.

[13] G. A. Rutten, unpublished computer program, Eindhoven University of Technology, 1984

Ms received: October 14, 1985

\section{Automatic Simulated Distillation of Heavy Petroleum Fractions up to $800^{\circ} \mathrm{C}$ TBP by Capillary Gas Chromatography}

\section{Part I: Possibilities and Limits of the Method}

\section{S. Trestianu*, G. Zilioli, A. Sironi, C. Saravalle, and F. Munari}

Carlo Erba Strumentazione, P.O. Box, 20090 Rodano, Milan, Italy

M. Galli

MEGA, Via Pola 10, 20010 S. Giorgio Su Legnano, Milan, Italy

\section{G. Gaspar}

Erba Science, 127-129 Rue de Paris, 91300 Massy, France

\section{J. M. Colin, J. L. Jovelin}

Compagnie Francaise de Rafinage, Centre de Recherche, P.O. Box 27, 76700 Harfleur, France

\section{Key Words:}

Gas chromatography

Capillary columns

Simulated distillation

\section{Summary}

The characterization of heavy petroleum fractions is essential for the design and improvement of cracking plants converting heavy feedstock into valuable "white" products. Conventional simulated distillation methods using packed columns are unsuitable for this purposes, being limited to boiling points up to about $600^{\circ} \mathrm{C}$. The method presented is able to cover a boiling points interval ranging from about $150^{\circ} \mathrm{C}$ up to around $800^{\circ} \mathrm{C}$. It employs a short, nonpolar, highly thermostable capillary column routinely operated at temperatures around $430^{\circ} \mathrm{C}$. The analytical system is based on a high temperature version of a fully automa-

\footnotetext{
Dedicated to Professor Kurt Grob on his 65th birthday.
}

tic, capillary dedicated gas chromatograph. The experimental data demonstrate that cold on-column injection is the sole sampling system suitable for such heavy compounds. The conversion of the retention times into boiling points, based on the use of low molecular weight polyethylenes, is extremely reliable, as demonstrated by the excellent retention time reproducibilities. The lower part (up to $550-600^{\circ} \mathrm{C}$ TBP) of the boiling point distribution curves of heavy petroleum fractions obtained on capillary columns fits well with the corresponding distribution curves based on packed column data. For the petroleum fractions fully eluted from the column the quantitative results obtained either using internal standards or by direct processing of the elution curves are in excellent agreement (less than 0.3 weight $\%$ differences). The method has been applied to the determination of the true boiling points corresponding to short path vacuum distillation (DISTACT) cut points over $300^{\circ} \mathrm{C}$. 